\title{
Development of an Automated Digestion and Droplet Deposition Microfluidic Chip for MALDI-TOF MS
}

\author{
Jeonghoon Lee, ${ }^{a}$ Harrison K. Musyimi, ${ }^{b}$ Steven A. Soper, ${ }^{\text {a,c,d }}$ \\ and Kermit K. Murray ${ }^{a}$ \\ a Department of Chemistry, Louisiana State University, Baton Rouge, Louisiana, USA \\ ${ }^{b}$ National Institute on Aging/National Institutes of Health, Baltimore, Maryland, USA \\ 'Department of Mechanical Engineering, Louisiana State University, Baton Rouge, Louisiana, USA \\ d Center for BioModular Multi-Scale Systems, Louisiana State University, Baton Rouge, Louisiana, USA
}

An automated proteolytic digestion bioreactor and droplet deposition system was constructed with a plastic microfluidic device for off-line interfacing to matrix assisted laser desorption/ ionization time-of-flight mass spectrometry (MALDI-TOF MS). The microfluidic chips were fabricated in poly(methyl methacrylate) (PMMA), using a micromilling machine and incorporated a bioreactor, which was $100 \mu \mathrm{m}$ wide, $100 \mu \mathrm{m}$ deep, and possessed a $4 \mathrm{~cm}$ effective channel length ( $400 \mathrm{~nL}$ volume). The chip was operated by pressure-driven flow and mounted on a robotic fraction collector system. The PMMA bioreactor contained surface immobilized trypsin, which was covalently attached to the UV-modified PMMA surface using coupling reagents $N$-(3-dimethylaminopropyl)- $N^{\prime}$-ethylcarbodiimide hydrochloride (EDC) and hydroxysulfosuccinimide (sulfo-NHS). The digested peptides were mixed with a MALDI matrix on-chip and deposited as discrete spots on MALDI targets. The bioreactor provided efficient digestion of a test protein, cytochrome $c$, at a flow rate of $1 \mu \mathrm{L} / \mathrm{min}$, producing a reaction time of $\sim 24 \mathrm{~s}$ to give adequate sequence coverage for protein identification. Other proteins were also evaluated using this solid-phase bioreactor. The efficiency of digestion was evaluated by monitoring the sequence coverage, which was $64 \%, 35 \%, 58 \%$, and $47 \%$ for cytochrome $c$, bovine serum albumin (BSA), myoglobin, and phosphorylase $b$, respectively. (J Am Soc Mass Spectrom 2008, 19, 964-972) @ 2008 American Society for Mass Spectrometry

$Q^{i}$ ignificant progress has been made toward the development of microchip-based technologies for proteomics through the integration of analytical processes into platforms that can provide rapid identification of proteins and the subsequent characterization of various post-translational modifications [1-4]. The small sample and reagent requirements, rapid analysis times, high throughput processing capabilities, and low operating costs are among the driving forces for the development of these systems [5-8]. Different microfluidic devices have been applied to specific aspects of protein processing, in particular, protein purification and separation, protein digestion, and protein identification by mass spectrometry [9].

There have been a number of approaches to on-line and off-line matrix-assisted laser desorption ionization mass spectrometry (MALDI-MS) integrated to chipbased devices [10-18]. The primary advantage of the MALDI approach compared with electrospray ionization (ESI) when coupling to microfluidic chips is the potential for multiplexing [19]. The directional control

Address reprint requests to Dr. Kermit K. Murray, Department of Chemistry, Louisiana State University, 232 Choppin Hall, Baton Rouge, LA 70802, USA. E-mail: kkmurray@lsu.edu of the ESI spray can be difficult with a high-density array of spray tips. Furthermore, microfluidic chip interfaces to ESI can suffer from stability problems when sprays are started or stopped $[20,21]$. This limits the speed of moving from one sample to another and therefore, limits throughput.

With recent advances in analytical methods for proteomics, attention has been directed toward development of efficient pretreatment protocols for protein identification [22]. Strategies for identifying proteins focus on accurate, sensitive, simple, and high throughput analyses achieved by either reducing processing time or with multi-channel devices [23, 24]. Trypsin digestion for protein sample preparation is the most frequently used step in proteomic analysis due to the robust nature of this enzyme and the extensive databases and software tools for trypsin digests of proteins $[25,26]$. However, the long sample incubation times required for trypsin digestion in solution and the extensive sample treatment steps result in long protein processing times. To overcome those obstacles, rapid in-solution digestion protocols have been developed using organic solvents to denature proteins or by applying higher incubation temperature to accelerate reaction time [27-30]. However, efficient protein identifi- 
cation from in-solution digestion of dilute protein samples can be difficult due to low proteolytic digestion rates, and background from autodigested trypsin that is typically observed in the mass spectra when a high concentration of trypsin is used.

As an alternative to in-solution digestion, bioreactors can be used to digest small quantities of separated proteins. Typically, the reaction time required for homogeneous solution tryptic digestions is tens of hours to achieve a sufficient population of peptide fragments for effective PMF because the enzyme-to-substrate ratio must be kept low to avoid interferences from autodigested trypsin [26]. To overcome this problem, enzymeimmobilization on solid supports for solid-phase bioreactors has been introduced [26, 31-33]. Many of these solid-phase bioreactors use immobilization of proteolytic enzymes through covalent attachment to supports or encapsulation within gel matrices. Compared with homogeneous reactors, solid-phase enzymatic bioreactors offer several advantages such as faster and simpler sample preparation steps, fewer enzyme autolysis products, good reproducibility, larger enzyme-tosubstrate molar ratios, high digestion efficiency, and the possibility of repeated use. Wang et al. [26] developed a microfluidic chip that was packed with trypsin-loaded beads in a fluidic channel. It was found that the bead-packed chip gave faster protein digestion and fewer trypsin autolysis products compared with a homogeneous reaction.

Functionalized 3-D support networks can also be made in situ [31-34], which overcomes the difficulty of packing beads into the microchannels. Typically, these in situ methods use a polymerization reaction of a monomer solution inside a channel to modify the support. Then, trypsin solution is infused into the bioreactor for about $24 \mathrm{~h}$ for complete immobilization. Peterson et al. [31] developed a porous organic polymer monolithic bioreactor as in situ approach that allowed trypsin to be immobilized covalently within the monolith using the azlactone functional groups of the monolith [32]. Kato et al. [33] reported a monolithic photopolymerized sol-gel column that was used to immobilize pepsin within a fused silica capillary for integration of protein digestion and identification by CE/MS. Recently, Huang et al. [34] described a similar device that utilized trypsin immobilized into a modified PMMA chip with zeolite nanoparticles using a silica sol-gel method. This bioreactor provided high surface areas for the immobilized enzyme, increasing the load level within the bioreactor. Even though a fast reaction time ranging from $5 \mathrm{~s}$ to $1 \mathrm{~h}$ was achieved, it required 12 to $24 \mathrm{~h}$ for enzyme immobilization. In addition to complex and time-consuming preparation, none of the above bioreactors have been adapted to MALDI target deposition for rapid and automated analysis.

In this study, we report on a simple microfluidic device that incorporated both trypsin digestion and MALDI matrix addition for spotting tryptic digests for MALDI-TOF MS analysis. We prepared a novel trypsin immobilized PMMA solid-phase microfluidic chip consisting of an open channel reactor and a coaxial collection tip. Also, we developed an off-line MALDI interface to combine matrix addition and deposition on a MALDI target using a robotic plate spotter modified to accept the effluent from the microfluidic chip. This system was applied for the digestion of proteins and deposition onto a MALDI target plate. The enzymatic bioreactor was used for the rapid digestion of a variety of proteins followed by off-line MALDI TOF MS detection of the generated peptides. The fabricated bioreactor included coaxial channels for mixing digested peptides with the matrix solution. The performance of this system was demonstrated using proteins cytochrome $c$, myoglobin, bovine serum albumin (BSA), and phosphorylase $b$ as model targets.

\section{Experimental}

\section{Materials}

The microfluidic chip was fabricated from PMMA, which was obtained from MSC (Melville, NY). Ammonium bicarbonate buffer (50 mM, pH 8.5) was purchased from Sigma (St. Louis, MO). N-(3-dimethylaminopropyl)- $N$ '-ethylcarbodiimide hydrochloride (EDC) and hydroxysulfosuccinimide (Sulfo-NHS), which were used to modify the surface of the PMMA microchannels, were obtained from Sigma and Pierce (Rockford, IL), respectively. Protein standards equine cytochrome $c$ (C-2506), equine myoglobin (M-1882), bovine serum albumin (BSA, A-0281), and phosphorylase $b$ from rabbit muscle (P-6635) were used and obtained from Sigma. Bradykinin (B-3259), which was used as an internal standard, trypsin (T-6567), isopropyl alcohol (IPA), and $\alpha$-cyano-4-hydroxycinnamic acid (CHCA) were also obtained from Sigma. Sodium phosphate buffer (100 mM, pH 7.0) and trifluoroacetic acid (TFA) were purchased from Fluka (Buchs, Switzerland). Silica tubes $(60 \times 0.28 \mathrm{~mm}$ o.d., $0.1 \mathrm{~mm}$ i.d. $)$ and stainless steel tubes $(60 \times 1.5 \mathrm{~mm}$ o.d., $0.5 \mathrm{~mm}$ i.d. $)$ were secured from Upchurch Scientific (Oak harbor, WA).

\section{Sample Preparation}

Cytochrome $c$, myoglobin, BSA, and phosphorylase $b$ were dissolved in $50 \mathrm{mM}$ ammonium bicarbonate buffer ( $\mathrm{pH}$ 8.2). To evaluate the chip performance, a stock solution of $50 \mu \mathrm{M}$ cytochrome $c$ was prepared. The stock solution was diluted to $10,5,2,1$, and $0.5 \mu \mathrm{M}$ with $50 \mathrm{mM}$ ammonium bicarbonate.

\section{Microchip Fabrication}

PMMA chips were microfabricated by a direct micromilling method [35]. The PMMA was cut into a $3 \mathrm{~cm} \times 5$ $\mathrm{cm}$ rectangular plate and a specified pattern of microstructures was milled onto the surface of the PMMA with a high precision micromilling machine (KERN 


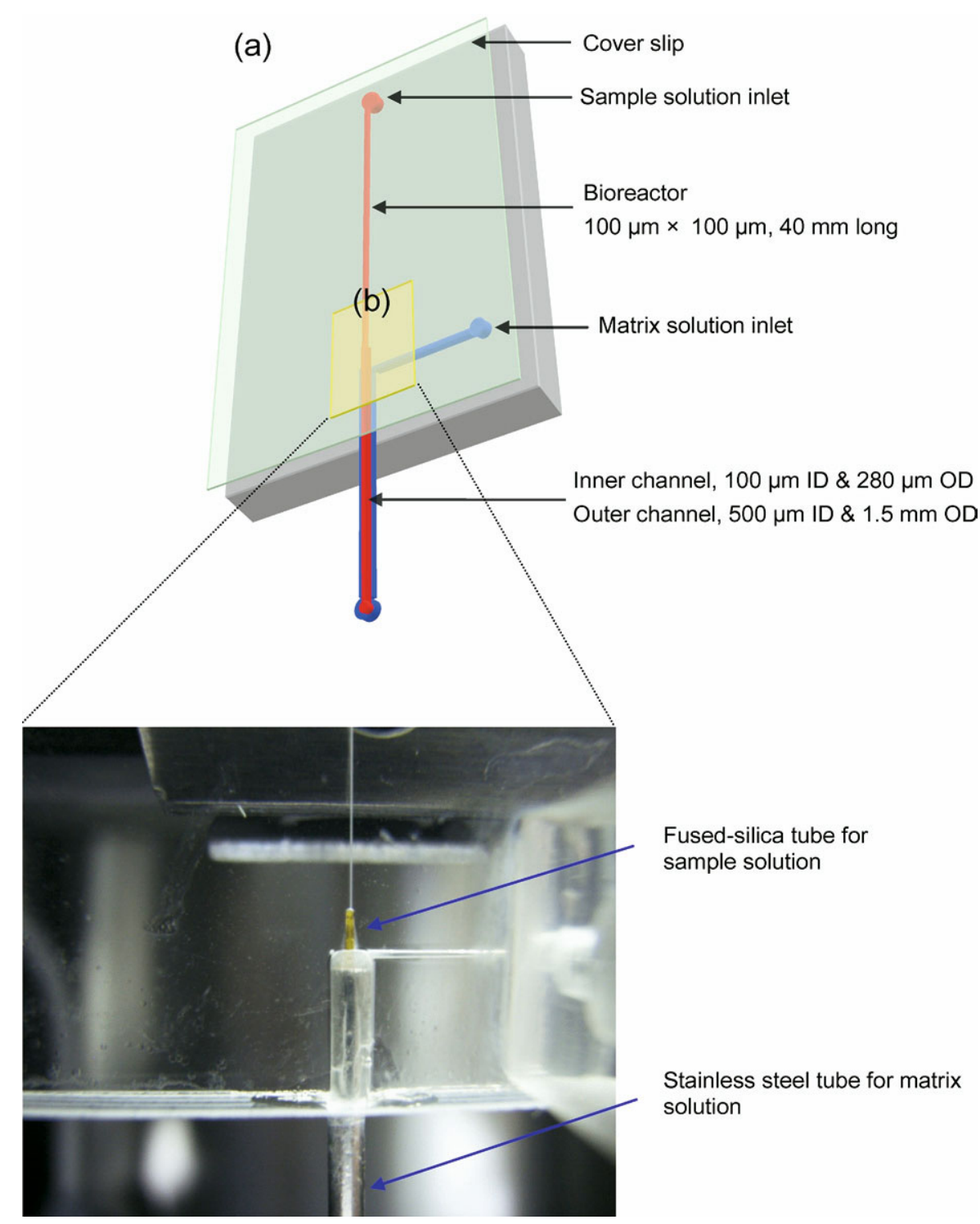

Figure 1. (a) Schematic of the PMMA microfluidic chip. The bioreactor measured $40 \mathrm{~mm} \times 100 \mu \mathrm{m}$ $\times 100 \mu \mathrm{m}$ and the solution of sample and matrix are loaded by syringe pumps. On the end of the bioreactor, coaxial tubes were sealed to mix digests with a matrix solution and to deposit onto a MALDI target plate. (b) Assembled tryptic digest microfluidic chip: components including PMMA chip and cover slip, inlet and outlet connectors, capillary and stainless steel tube.

MNP 2522; KERN Mikro-und Feinwerktechnik, Murnau, Germany). The micromilling machine was fitted with a laser measuring system (Laser Control NT; Blum-Novotest GmbH, Ravensburg, Germany) for automatic determination of tool length and radius and also an optical microscope (Zoom 6000; Navitar, Rochester, NY) for monitoring the micromilling process. The micromilling was operated at $40,000 \mathrm{rpm}$ and a feed rate of 1 to $20 \mathrm{~mm} / \mathrm{min}$ using a $50 \mu \mathrm{m}$ carbide bit (McMaster-Carr or Quality Tools Hammond, LA). After milling, the final device was ultrasonically cleaned with water and IPA and air dried. The PMMA chip was designed to fit into the stationary mount of a robotic fraction collector system (Probot; Dionex, Sunnyvale, $\mathrm{CA})$; the MALDI plate translated in the $\mathrm{x} / \mathrm{y}$ plane for spot deposition. Two PMMA blocks were tapped to accept $1 / 16$ in. tube fittings, which were epoxy glued to the microchip. A schematic and photograph of the assembled chip is shown in Figure 1.

The PMMA chip surfaces were activated for functional attachment of the proteolytic enzyme by exposing the microfabricated PMMA substrate and cover slip to a $254 \mathrm{~nm}$ UV lamp at $15 \mathrm{~mW} \mathrm{~cm}$ cor $^{-2} 20 \mathrm{~min}$ [36]. This was followed by inserting stainless steel and silica tubes into guide channels on the PMMA substrate and thermally annealing the UV exposed $0.125 \mathrm{~mm}$ PMMA cover slip to the substrate at $98^{\circ} \mathrm{C}$ for $20 \mathrm{~min}$ [35]. The assembled chip was then rinsed with deionized water and air-dried. Then, the UV-modified channels were chemically treated with a mixture of $5 \mathrm{mM}$ EDC and 5 
$\mathrm{mM}$ sulfo-NHS solution for $15 \mathrm{~min}$. Finally, trypsin was immobilized onto the surface of the UV-exposed microchannels by inserting a $20 \mu \mathrm{M}$ trypsin solution prepared in a $100 \mathrm{mM}$ phosphate buffer (pH 7.0) into the PMMA bioreactor channel for $2 \mathrm{~h}$. The chip was ready for immediate use or could be refrigerated for future use.

\section{Instrumentation}

The automated deposition of effluent from the microfluidic bioreactor chip onto a MALDI target plate was accomplished with a micro fraction collector. A 49-position or a 100-position MALDI target plate was used for sample spotting. Micro-drops from the microchip were automatically fractioned for $20 \mathrm{~s}$ per spot onto MALDI targets using the micro fraction collection system.

Mass spectra of the microchip fractions were recorded on a Bruker OmniFLEX MALDI-TOF mass spectrometer (Bruker Daltonik, Bremen, Germany) operated in reflectron mode with a pulsed nitrogen laser. The total acceleration voltage was $19 \mathrm{kV}$. Positive ions were detected and 50 single-shot spectra were acquired from each sample spot. Data processing was performed with XMASS 5.0 (Bruker), provided by the mass spectrometer manufacturer.

\section{Assembly of the Off-Line MALDI Microfluidic Interface}

The PMMA microfluidic chip was mounted in the micro fraction collector for protein digestion and deposition of the digests with a matrix solution on the MALDI plate. The chip had a coaxial matrix/analyte mixing system with the analyte exiting the chip through a $100 \mu \mathrm{m}$ i.d. and $280 \mu \mathrm{m}$ o.d. silica capillary tube, which was surrounded by a $4 \mathrm{~cm}$ long stainless steel tube that was $500 \mu \mathrm{m}$ i.d. and $1.5 \mathrm{~mm}$ o.d. with a tapered tip. The analyte flowed through an inner tube and the matrix flowed through an outer tube and was mixed at the point of target deposition. A syringe pump (Model 11; Harvard Apparatus, Holliston, MA) was used to supply the microchip with a protein solution. Solutions of cytochrome $c$, myoglobin, BSA, and phosphorylase $b$ in $50 \mathrm{mM}$ ammonium bicarbonate buffer solution were driven through the trypsin immobilized PMMA microchannel by a syringe pump at various volume flow rates. MALDI matrix was added to the microchip reservoir via a syringe pump at a flow rate of $5 \mu \mathrm{L} / \mathrm{min}$. The MALDI matrix solution consisted of 5 $\mathrm{mg} / \mathrm{mL}$ CHCA dissolved in $60 \%$ acetonitrile with the addition of $0.1 \%$ TFA containing an internal standard of bradykinin $(5 \mu \mathrm{M})$. Effluent from the microchip was deposited onto the MALDI target plate by the micro fraction collector and then analyzed off-line by MALDITOF MS. Fingerprinting and identification of the proteins was accomplished on the basis of the MSDB database using the MASCOT search program (Matrix
Science, London, United Kingdom) from the peptides generated from the digest. A mass deviation of $<0.25$ $\mathrm{Da}$ and one missed cleavage were allowed in the database searches.

\section{Results and Discussion}

\section{Off-Line Microfluidic Chip Interface to MALDI-TOF MS}

Cytochrome $c$ was used as a model protein for evaluating the performance of the automated tryptic digestion and droplet deposition system. A $10 \mu \mathrm{M}$ cytochrome $c$ solution in $50 \mathrm{mM}$ ammonium bicarbonate buffer was pumped through the solid-phase bioreactor at a flow rate of $1 \mu \mathrm{L} / \mathrm{min}$ using a syringe pump. The bioreactor was an open channel design and was $4 \mathrm{~cm}$ long (100 $\mu \mathrm{m}$ width and $100 \mu \mathrm{m}$ depth of channel) with a total reactor volume of $400 \mathrm{~nL}$ containing surfaceimmobilized trypsin. The effluent from the bioreactor was combined with a matrix solution on-chip delivered by a separate syringe pump module and automatically spotted onto a MALDI plate using a robotic fraction collector system. The deposition time of each fraction was $20 \mathrm{~s}$ and each drop had a total volume of $2.0 \mu \mathrm{L}$, which consisted of analyte with matrix solution mixed in a ratio of 1:5 (vol/vol). Therefore, each drop consisted of approximately one bioreactor volume. The spot sizes deposited were $1.5 \mathrm{~mm}$ in diameter with a standard deviation of $\pm 0.2 \mathrm{~mm}$. The hold-up volume of this system was estimated to be $\sim 0.3 \mu \mathrm{L}$, which was primarily from the silica capillary tip used for deposition. The first fraction deposited onto the MALDI plate contained only matrix as confirmed by mass spectrometry; digested peptides could be obtained after the second fraction deposition at the flow rate used (1 $\mu \mathrm{L} / \mathrm{min})$.

\section{MALDI Analysis of Solid-Phase Bioreactor Digested Cytochrome $C$}

Each fraction obtained by the digestion and droplet system was analyzed by MALDI-TOF MS. The $10 \mu \mathrm{M}$ solution of cytochrome $c$ was pumped through the bioreactor at a flow rate of $1 \mu \mathrm{L} / \mathrm{min}$, which afforded a residence time within the reactor of $24 \mathrm{~s}$. Eleven fragments containing 70 out of the 104 possible amino acids of cytochrome $c$ were obtained at $60 \mathrm{~s}$ fraction, producing a sequence coverage of $67 \%$. Peptide fragments were assigned on the basis of the MSDB database using the MASCOT search engine.

This sequence coverage identification process was evaluated by the probability-based Mowse score [37, 38], which is defined as; $-10 \log (P)$, where $P$ is the probability that the match is a random event $(P<0.05)$. This score represents the accuracy of a peptide mass fingerprint hit. The magnitude of the score is determined by the size of the database used, number of peptides, and the size of the protein. In our search using 


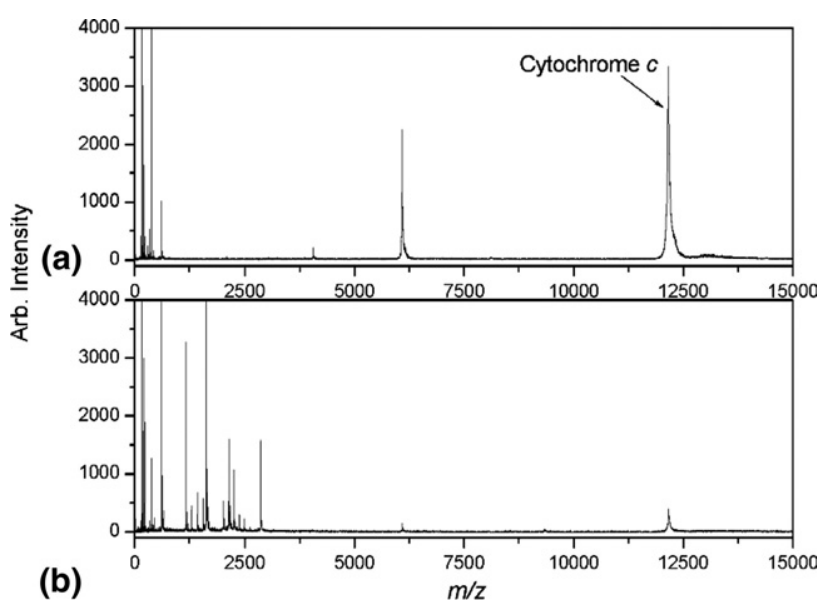

Figure 2. MALDI-TOF MS spectra obtained from (a) intact cytochrome $c$ and (b) its tryptic digest at $60 \mathrm{~s}: 20 \mu \mathrm{M}$ in $50 \mathrm{mM}$ ammonium bicarbonate buffer; flow rate, $1 \mu \mathrm{L} / \mathrm{min}$; deposition time, $20 \mathrm{~s}(6.6 \mathrm{pmol})$.

digested mass lists of cytochrome $c$, Mowse scores greater than 78 are considered significant identifiers of the target protein. The mass spectrum in Figure 2 corresponds to a Mowse score of 137 and a sequence coverage of $67 \%$. Thus, the identified peptides matched the cytochrome $c$ sequence with a high degree of certainty using our open channel bioreactor when operated at a volume flow rate of $1 \mu \mathrm{L} / \mathrm{min}$. Although the digestion efficiency of this bioreactor was high, not all of the peptides were identified, which may be due to incomplete digestion for protease-inaccessible proteins, solubility of digested peptides, and lack of a denaturation step in the bioreactor protocol [39]. Sequence coverage ranging from $18 \%$ to $95 \%$ have been reported for in-solution digestion of cytochrome $c$, which requires $15 \mathrm{~min}$ to $24 \mathrm{~h}$ reaction time [25, 29, 40].

The extent of protein reaction in the microfluidic chip was evaluated by comparing the mass spectrum of the unreacted protein with that of the digested protein from the chip. Figure 2 shows the mass spectra of 6.6 pmol cytochrome $c$ flowed through the chip and deposited on the MALDI target. The mass spectra are from a fraction obtained $60 \mathrm{~s}$ after injection using MALDI-TOF with linear mode. The chip used for Figure 2a was not derivatized with trypsin and the intact protein is observed. Figure $2 b$ was obtained from a chip with $a$ trypsin derivatized surface and tryptic fragments are observed. The different ionization efficiency for peptides and proteins and the possibility of competitive ionization make a quantitative determination of the efficiency of the digestion difficult; however the significant decrease in the protein signal suggests that the extent of reaction is quite high.

We next evaluated the effects of sample flow rate, which changes the residence time, on the extent of protein digestion in the solid-phase bioreactor by monitoring the sequence coverage. The flow rate of cytochrome $c$ solution was set to $0.5,1,2$, and $5 \mu \mathrm{L} / \mathrm{min}$, corresponding to residence times of $48,24,12$, and $4.8 \mathrm{~s}$, respectively. The mass spectra obtained from cytochrome $c$ digested at these different flow rates are shown in Figure 3. As seen in this figure, the digestion of cytochrome $c$ was more efficient at lower flow rates as evidenced by a larger number of peptide peaks in the mass spectrum. Mowse scores were 181 for 48 s residence time with $75 \%$ sequence coverage, 137 for $24 \mathrm{~s}$ residence time with $67 \%$ sequence coverage, 128 for $12 \mathrm{~s}$ residence time with $59 \%$ sequence coverage, and 101 for 4.8 s residence time with $42 \%$ sequence coverage.

The reaction rate for heterogeneous bioreactors is primarily determined by the mass transport of reactant to the surface and enzyme activity [41, 42]. In the open channel, mass transport plays a major role in determining overall reaction rate at higher flow velocities due to less frequent encounters between the solution-phase protein and the surface-immobilized enzyme [43, 44]. Slovakova et al. [43] described a methodology for efficient digestion by introducing a bioreactor packed with immobilized trypsin beads to reduce diffusional distances and increase the number of encounters between the reactant and substrate. In their report, the sequence coverage of human growth hormone selected as a model protein increased from $7 \%$ to $44 \%$ with increased residence time ranging from $141 \mathrm{~s}$ to $564 \mathrm{~s}$.

In a previous study, Duan et al. [44] reported increased digestion with greater residence time of cytochrome $c$ in a monolithic enzymatic bioreactor prepared by in situ polymerization of acrylamide, $N$-acryloxysuccinimide, and ethylene dimethacrylate. In their report, the sequence coverage of cytochrome $c$ they obtained at a residence time of $7 \mathrm{~s}(1 \mu \mathrm{L} / \mathrm{min})$ was $54.8 \%$. In our system, $67 \%$ sequence coverage with the Mowse score of 137 at the flow rate of $1.0 \mu \mathrm{L} / \mathrm{min}$ (24 s residence time) was adequate to identify cytochrome $c$ using an

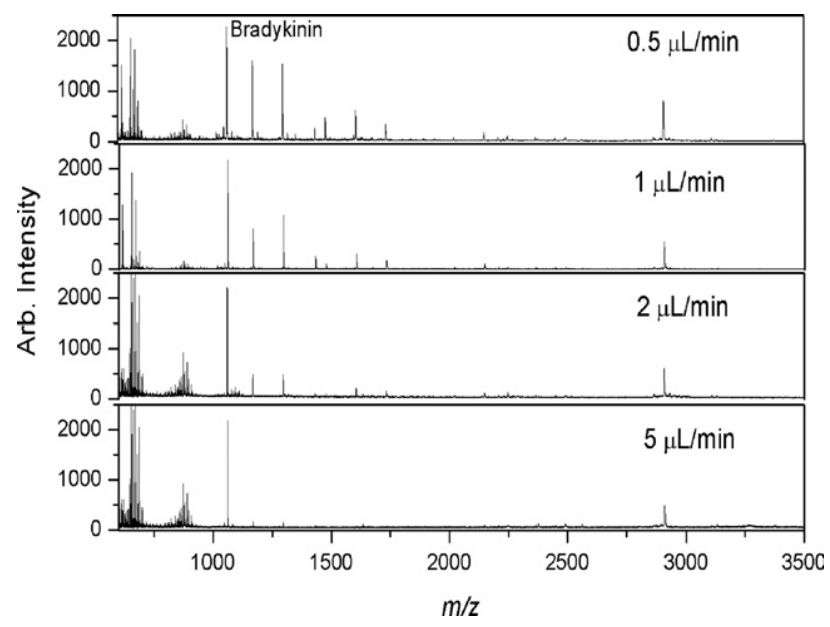

Figure 3. MALDI-TOF MS spectra obtained from digests of cytochrome $c$ at different flow rates: $10 \mu \mathrm{M}$ in $50 \mathrm{mM}$ ammonium bicarbonate buffer; deposition time, 40, 20, 10, and $4 \mathrm{~s}$ for flow rate, $0.5,1,2$, and $5 \mu \mathrm{L} / \mathrm{min}$, respectively. Bradykinin is an internal standard. At low flow rate (long residence time) the intensity of peaks was larger compared to high flow rates. 

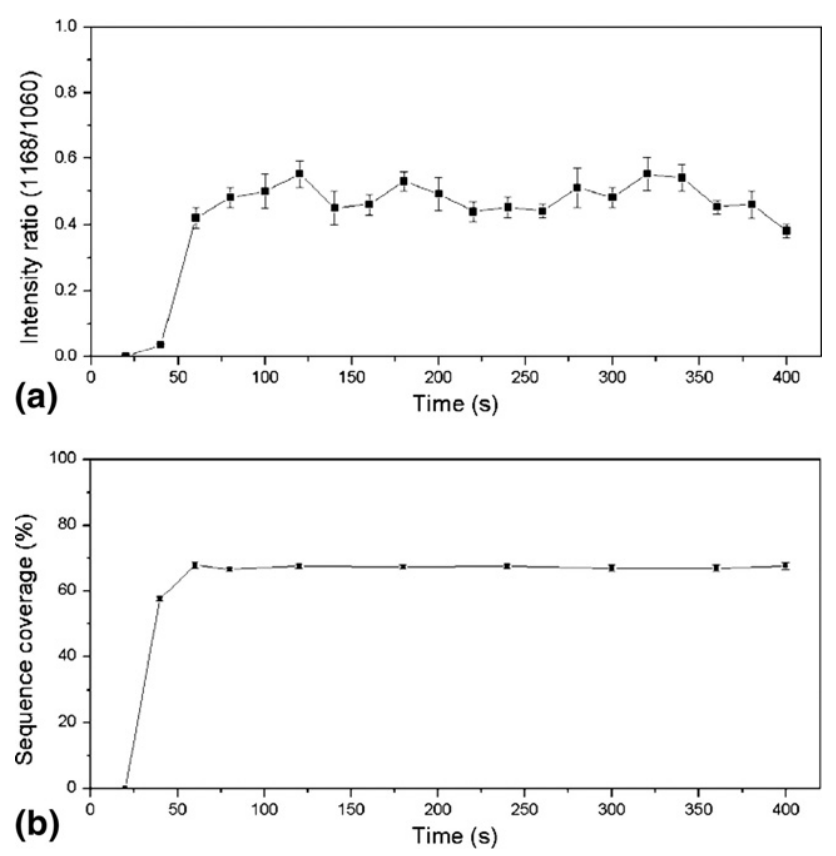

Figure 4. Evaluation of microfluidic chip performance for the digestion of cytochrome $c$ as a function of time: (a) intensity ratio of selected peak $(\mathrm{m} / \mathrm{z}$ 1168) using internal standard, bradykinin $(\mathrm{m} / \mathrm{z}$ 1060), and (b) sequence coverage; $10 \mu \mathrm{M}$ in $50 \mathrm{mM}$ ammonium bicarbonate buffer; flow rate, $1 \mu \mathrm{L} / \mathrm{min}$; deposition time, $20 \mathrm{~s}$.

open channel reactor that did not require fabrication of a 3-D support network for the enzyme. In subsequent experiments reported herein, we utilized a flow rate of $1.0 \mu \mathrm{L} / \mathrm{min}$ since it produce a Mowse score adequate for protein identification.

\section{Digestion Capacity of the Solid-Phase Open Channel Bioreactor}

We next continuously monitored the peptides generated from a cytochrome $c$ trypsin digest from the bioreactor as a function of time at $20 \mathrm{~s}$ intervals to determine the stability of the bioreactor system. The immobilized trypsin was continuously exposed to a solution containing $10 \mu \mathrm{M}$ cytochrome $c$ prepared in 50 $\mathrm{mM}$ ammonium bicarbonate buffer at a flow rate of 1 $\mu \mathrm{L} / \mathrm{min}$. A total of $7 \mu \mathrm{L}$ of $10 \mu \mathrm{M}$ cytochrome $c$ was flowed through the bioreactor using a syringe pump with $\sim 7 \mathrm{~min}$ of infusion. Twenty fractions were collected on the MALDI target plate and each fraction contained peptides from 3.3 pmol of cytochrome $c$ injected into the reactor. The intensity and sequence coverage as a function of sampling interval obtained from the mass spectra data are shown in Figure 4 . The intensity of the peak at $\mathrm{m} / \mathrm{z} 1168$, which is one of the major peptide peaks corresponding to residues 28-38 of cytochrome $c$ (TGPNLHGLFGR), was normalized to the intensity of the internal standard, bradykinin $(\mathrm{m} / \mathrm{z} 1060$, $8.3 \mathrm{pmol})$, and this value was used as an indication of the extent of digestion. As seen in Figure $4 \mathrm{a}$, the $\mathrm{m} / \mathrm{z}$
1168 peak was observed $40 \mathrm{~s}$ (including hold-up time of $18 \mathrm{~s}$ ) after $0.4 \mu \mathrm{L}$ of cytochrome $c$ was injected into the bioreactor. The normalized peak intensity ratio reached a maximum after $1 \mathrm{~min}$ and remained at that within the standard deviation of the measurement. During the continuous injection of cytochrome $c$, the peak intensity ratio was nearly the same, which indicates that the activity of trypsin covalently attached onto the PMMA surface remained high during this experiment. In Figure $4 \mathrm{~b}$, it can be seen that the sequence coverage of cytochrome $c$ was $53 \%$ at $40 \mathrm{~s}$. The fraction at $60 \mathrm{~s}$ had a sequence coverage of $67 \%$ and remained at this value during the rest of this experimental run. Note that this value is appropriate for confirmation of cytochrome $c$ based on Mowse score. The fraction at $100 \mathrm{~s}$ did not produce significant differences from the fraction at $60 \mathrm{~s}$. In contrast with in-solution digestion which cannot be reused, the solid-phase bioreactor could be reused without noticeable loss of activity of immobilized enzyme [7, 33, 45]. During three independent experimental runs similar to that shown in Figure 4 using the same bioreactor, the activity remained relatively constant after rinsing the bioreactor with $50 \mathrm{mM}$ ammonium bicarbonate between experimental runs. The memory effect of the bioreactor was checked between runs of cytochrome $c$ solutions by collecting and analyzing the first spot from the bioreactor. As can be seen in the figure, these blank spots did not result in any mass spectral peaks due to carryover.

Typically, proteins are digested in solution at an enzyme-to-substrate molar ratio of $1: 50$ for $24 \mathrm{~h}$ of incubation [46]. When a relatively low enzyme-tosubstrate molar ratio is employed, the enzymatic reaction has low efficiency $[40,46]$; however, this low molar ratio is necessary to avoid excessive autodigestion of trypsin. Lazar et al. [40] discussed the effects of trypsin concentration on the rate of digestion in solution. In their work, in-solution digestion of various proteins was accomplished using enzyme-to-substrate molar ratios of 1:1 to 1:20 for $15 \mathrm{~min}$ to $24 \mathrm{~h}$ of incubation. For the highest enzyme-to-substrate mole ratio (1:1), adequate digestion could be obtained after 15 min of digestion. The sequence coverage of cytochrome $c$ at that mole ratio was $88 \%$ to $95 \%$ using ESI-TOF MS. In our experiment, 8 pmol trypsin was used for immobilization onto the surface of the UV-exposed microchannel. The amount of trypsin immobilized depends on the molecular size of trypsin and the surface density of the carboxylate group on the substrate. In a previous study, McCarley et al. [36] described the effect of UV-exposure time on carboxylic acid coverage on PMMA surfaces, which was determined to be $1 \times 10^{-9} \mathrm{~mol} / \mathrm{cm}^{2}$ after an exposure time of $20 \mathrm{~min}$. Trypsin is a globular protein of $24 \mathrm{kDa}$ with a diameter of about $4 \mathrm{~nm}$ [47]. If it is assumed that trypsin is attached to the PMMA surface in a monolayer, the quantity of trypsin immobilized onto the surface of our bioreactor can be calculated by taking into account the carboxylic acid coverage, the size of trypsin, and the surface area. Using these values, 

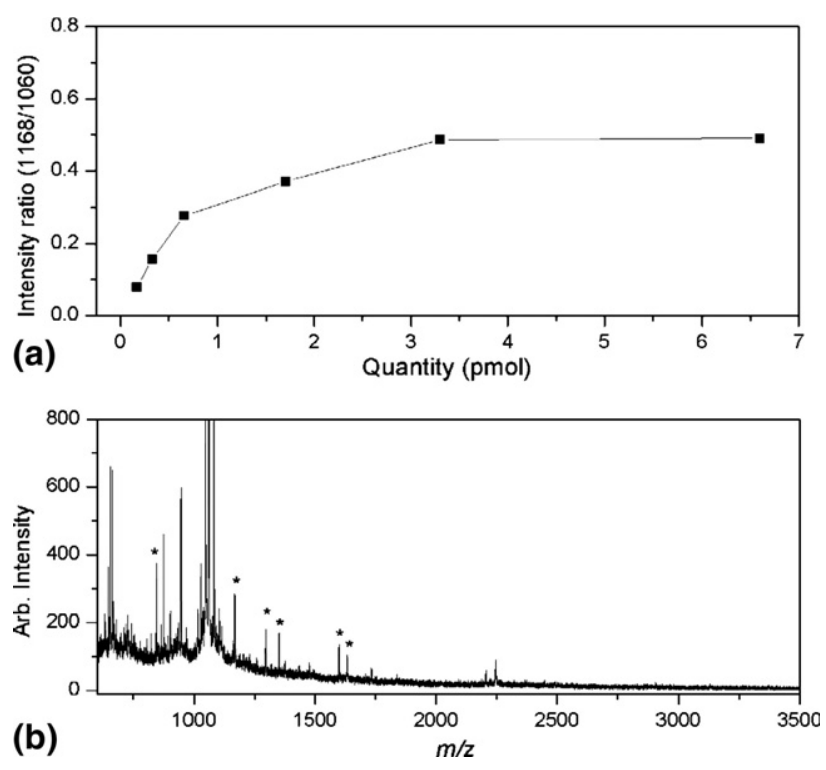

Figure 5. (a) Relative intensity for the tryptic digests of cytochrome $c$ as a function of quantity in pmol: internal standard, bradykinin $(\mathrm{m} / \mathrm{z}$ 1060); flow rate, $1 \mu \mathrm{L} / \mathrm{min}$; deposition time, $20 \mathrm{~s}$. (b) MALDI-TOF MS spectrum of tryptic digest of $0.5 \mu \mathrm{M}$ cytochrome $c$ in $50 \mathrm{mM}$ ammonium bicarbonate buffer (170 fmol).

it is found that the reactor contains 2.1 pmol trypsin. The $10 \mu \mathrm{M}$ cytochrome $c$ used to test the performance of the bioreactor corresponds to 4 pmol protein, thus the enzyme-to-substrate mole ratio was nearly 1:2 for a single enzymatic reaction.

\section{Effects of the Mass Quantity of Cytochrome c on Sequence Coverage}

Figure 5a shows the intensity ratio of peptide peaks normalized to the internal standard, bradykinin, obtained from different amounts of cytochrome $c$. The digest peak at $\mathrm{m} / \mathrm{z} 1168$ was normalized using the internal standard peak, which resulted from 8.3 pmol of bradykinin. As shown in Figure 5a, the intensity ratio increased with increasing quantity of cytochrome $c$. At $170 \mathrm{fmol}$ of cytochrome $c$ (Figure 5b), peptide peaks indicated with asterisks were identified. The signal-tonoise ratio (SNR) of identified peaks was above 10 except for the peak at $m / z$ 1633.3, where the SNR was 7. Below 0.66 pmol, the sequence coverage was $57 \%$, and it reached $67 \%$ at 3.3 pmol, where the best sequence coverage was obtained. Above 3.3 pmol of cytochrome $c$, the peak intensity ratio was saturated most likely due to longitudinal diffusion of proteins at high concentration being restricted, reducing mass transport to the surface [48].

\section{Tryptic Digestion of Proteins}

The performance of the bioreactor system was further evaluated for proteins with different molecular weights and isoelectric points. The immobilized trypsin biore- actor was exposed to solutions containing $10 \mu \mathrm{M}$ BSA (66 kDa), $10 \mu \mathrm{M}$ myoglobin (16.5 kDa), and $10 \mu \mathrm{M}$ phosphorylase $b(97 \mathrm{kDa})$ prepared in $50 \mathrm{mM}$ ammonium bicarbonate buffer. Each deposited spot contained digested peptides from 3.3 pmol of protein infused at $1.0 \mu \mathrm{L} / \mathrm{min}$ flow rate and a $20 \mathrm{~s}$ deposition time. The mass spectra of the trypsin-digested proteins are shown in Figure 6. The microfluidic chip coupled to the MALDI-TOF MS analysis produced an average sequence coverage of $35 \%, 58 \%$, and $47 \%$ for BSA, myoglobin, and phosphorylase $b$, respectively. Peptide assignments for each protein are provided in the Supplemental Information (which can be found in the electronic version of this article). The probability-based Mowse score $(P<0.05)$ was 143 for BSA, 121 for myoglobin, and 319 for phosphorylase $b$. Based on sequence coverages and Mowse scores of these proteins, the identified peptides matched target proteins with high degree of certainty. Compared with cytochrome $c$, lower sequence coverage was obtained for these proteins, which was likely due to their proteolysisresistant structures $[49,50]$. BSA is typically difficult to digest because its tertiary structure is stabilized by disulfide bonds. Myoglobin is also resistant to tryptic digestion at the stabilized hydrophobic interior and phosphorylase $b$ has a relatively high molecular weight with a folded structure.

\section{Conclusions}

We have described the coupling of a PMMA microfluidic chip to MALDI-TOF MS for an automated enzymatic digestion and droplet deposition system. This system integrates steps for proteomic analysis using MALDI-TOF MS such as digestion, mixing with a

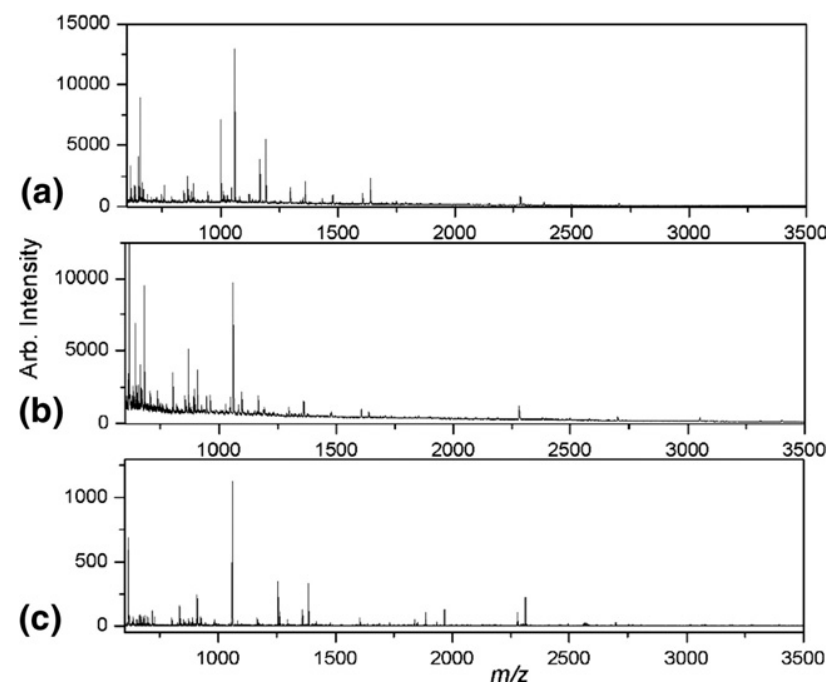

Figure 6. MALDI-TOF MS spectra of tryptic digests of (a) BSA, (b) myoglobin, and (c) phosphorylase $b$ using the automated digestion chip. Proteins are $10 \mu \mathrm{M}$ in $10 \mathrm{mM}$ ammonium bicarbonate buffer; flow rate, $1 \mu \mathrm{L} / \mathrm{min}$; deposition time, $20 \mathrm{~s}(3.3$ pmol); sequence coverage of BSA, myoglobin, and phosphorylase $b$ was 35,58 , and $47 \%$, respectively. 
matrix solution, and depositing onto a MALDI target plate. Compared with several reported microfluidic devices for protein digestion that require reaction times of 3 to $10 \mathrm{~min}$ to achieve the desired sequence coverage $[26,43,49,51]$, our automated digestion system with matrix mixing and spotting affords comparable coverage after a residence time of less than $1 \mathrm{~min}$. In addition, the open channel format obviates the need for producing 3-D supports in the reactor or packing the reactor with beads. These protein tryptic digest results show that our automated digestion and deposit microchip system coupled with a MALDI-TOF MS can be successfully applied to a wide range of proteins with highthroughput and sensitive detection of peptides for proteomic research. This solid-phase bioreactor has the potential for use with chip-based separations using bottom-up proteomics as well as a shotgun proteomics. For example, 2-D microfluidic separations of proteins have been developed by our group [52]. One can also envision an on-chip 2-D separation (reversed-phase plus ion-exchange separation) for peptides that can be employed along with the solid-phase digestion and deposition system.

Several approaches to increase efficiency of digestion are being developed. In a bioreactor, digestion efficiency depends on the geometry, digestion temperature, the compositions of digestion solvents, and the applied voltage. These parameters must be optimized to achieve fast and efficient digestion. We are also currently working on integrating this system to a multidimensional microchip-based separation system. To implement this interface, the limit of detection must be improved. One way this can be accomplished is with a hydrophobic MALDI target $[53,54]$ to obtain smaller deposited spot sizes. Under these conditions, the deposition volume can be reduced to achieve low volume fractions with a higher local concentration. We are evaluating a continuous deposition interface, which has the potential for low volume sample deposition from the bioreactor [55-57], thereby enhancing sensitivity [58].

\section{Acknowledgments}

The authors thank Mr. Jason Guy of the Center for BioModular Microsystems in the Mass Spectrometry Facility at Louisiana State University for his technical help. They also acknowledge Dr. Azeem Hasaan of the Mass Spectrometry Facility in the Louisiana State University for allowing the use of the mass spectrometry facilities.

\section{References}

1. Figeys, D.; Pinto, D. Proteomics on a Chip: Promising Developments. Electrophoresis 2001, 22, 208-216.

2. Li, J.; LeRiche, T.; Tremblay, T.-L.; Wang, C.; Bonneil, E.; Harrison, D. J.; Thibault, P. Application of Microfluidic Devices to Proteomics Research. Mol. Cell. Proteom. 2002, 1, 157-168.

3. Lion, N.; Rohner, T. C.; Dayon, L.; Arnaud, I. L.; Damoc, E.; Youhnovski, N.; Wu, Z.-Y.; Roussel, C.; Josserand, J.; Jensen, H.; Rossier, J. S.; Przybylski, M.; Girault, H. H. Microfluidic Systems in Proteomics. Electrophoresis 2003, 24, 3533-3562.

4. DeVoe, D. L.; Lee, C. S. Microfluidic Technologies for MALDI-MS in Proteomics. Electrophoresis 2006, 27, 3559-3568.
5. Duffy, D. C.; McDonald, J. C.; Schueller, O. J. A.; Whitesides, G. M. Rapid Prototyping of Microfluidic Systems in Poly(Dimethylsiloxane). Anal. Chem. 1998, 70, 4974-4986.

6. Ekström, S.; Önnerfjord, P.; Nilsson, J.; Bengtsson, M.; Laurell, T.; Marko-Varga, G. Integrated Microanalytical Technology Enabling Rapid and Automated Protein Identification. Anal. Chem. 2000, 72, 286-293.

7. Liu, Y.; Lu, H.; Zhong, W.; Song, P.; Kong, J.; Yang, P.; Girault, H. H.; Liu, B. Multilayer-Assembled Microchip for Enzyme Immobilization as Reactor Toward Low-Level Protein Identification. Anal. Chem. 2006, 78, 801-808.

8. Ethier, M.; Hou, W.; Duewel, H. S.; Figeys, D. The Proteomic Reactor: A Microfluidic Device for Processing Minute Amounts of Protein Prior to Mass Spectrometry Analysis. J. Proteome Res. 2006, 5, 2754-2759.

9. Freire, S. L. S.; Wheeler, A. R. Proteome-on-a-Chip: Mirage, or on the Horizon? Lab. Chip. 2006, 6, 1415-1423.

10. Murray, K. K.; Russell, D. H. Liquid Sample Introduction for MatrixAssisted Laser Desorption Ionization. Anal. Chem. 1993, 65, 2534-2537.

11. Musyimi, H. K.; Guy, J.; Narcisse, D. A.; Soper, S. A.; Murray, K. K Direct Coupling of Polymer-Based Microchip Electrophoresis to Online MALDI-MS Using a Rotating Ball Inlet. Electrophoresis 2005, 26, 47034710

12. Önnerfjord, P.; Ekström, S.; Bergquist, J.; Nilsson, J.; Laurell, T.; MarkoVarga, G. Homogeneous Sample Preparation for Automated High Throughput Analysis with Matrix-Assisted Laser Desorption/Ionization Time-of-Flight Mass Spectrometry. Rapid Commun. Mass Spectrom. 1999, 13, 315-322.

13. Ørsnes, H.; Graf, T.; Degn, H.; Murray, K. K. A Rotating Ball Inlet for On-Line MALDI Mass Spectrometry. Anal. Chem. 2000, 72, 251-254.

14. Preisler, J.; Foret, F.; Karger, B. L. On-Line MALDI-TOF MS Using a Continuous Vacuum Deposition Interface. Anal. Chem. 1998, 70, 52785287.

15. Zhang, X.; Narcissea, D. A.; Murray, K. K. On-Line Single Droplet Deposition for MALDI Mass Spectrometry. J. Am. Soc. Mass Spectrom. 2004, 15, 1471-1477.

16. Brivio, M.; Tas, N. R.; Goedbloed, M. H.; Gardeniers, H. J. G. E. Verboom, W.; Van de Berg, A.; Reinhoudt, D. N. A MALDI-Chip Integrated System with a Monitoring Window. Lab. Chip. 2005, 5 , $378-381$.

17. Liu, J.; Tseng, K.; Garcia, B.; Lebrilla, C. B.; Mukerjee, E.; Collins, S. Smith, R. Electrophoresis Separation in Open Microchannels. A Method for Coupling Electrophoresis with MALDI-MS. Anal. Chem. 2001, 73, 2147-2151.

18. Hirschberg, D.; Tryggvason, S.; Gustafsson, M.; Bergman, T.; Swedenborg, J.; Hedin, U.; Jörnvall, H. Identification of Endothelial Proteins by MALDI-MS Using a Compact Disc Microfluidic System. Protein J. 2004, 23, 263-271.

19. Lazar, I. M.; Grym, J.; Foret, F. Microfabricated Devices: A New Sample Introduction Approach to Mass Spectrometry. Mass Spectrom. Rev. 2006 $25,573-594$.

20. Nilsson, S.; Svedberg, M.; Pettersson, J.; Björefors, F.; Markides, K. Nyholm, L. Evaluations of the Stability of Sheathless Electrospray Ionization Mass Spectrometry Emitters Using Electrochemical Techniques. Anal. Chem. 2001, 73, 4607-4616.

21. Svedberg, M.; Pettersson, A.; Nilsson, S.; Bergquist, J.; Nyholm, L.; Nikolajeff, F.; Markides, K. Sheathless Electrospray from Polymer Microchips. Anal. Chem. 2003, 75, 3934-3940.

22. Massolini, G.; Calleri, E. Immobilized Trypsin Systems Coupled OnLine to Separation Methods: Recent Developments and Analytical Applications. J. Sep. Sci. 2005, 28, 7-21.

23. Peterson, D. S.; Rohr, T.; Svec, F.; Fréchet, J. M. J. High-Throughput Peptide Mass Mapping Using a Microdevice Containing Trypsin Immobilized on a Porous Polymer Monolith Coupled to MALDI TOF and ESI TOF Mass Spectrometers. J. Proteome Res. 2002, 1, 563-568.

24. Nägele, E.; Vollmer, M. Coupling of Nanoflow Liquid Chromatography to Matrix-Assisted Laser Desorption/Ionization Mass Spectrometry: Real-Time Liquid Chromatography Run Mapping on a MALDI plate. Rapid Commun. Mass Spectrom. 2004, 18, 3008-3014.

25. Duan, J.; Liang, Z.; Yang, C.; Zhang, J.; Zhang, L.; Zhang, W.; Zhang, Y. Rapid Protein Identification Using Monolithic Enzymatic Microreactor and LC-ESI-MS/MS Proteomics 2006, 6, 412-419.

26. Wang, C.; Oleschuk, R.; Ouchen, F.; Li, J.; Thibault, P.; Harrison, D. J. Integration of Immobilized Trypsin Bead Beds for Protein Digestion within a Microfluidic Chip Incorporating Capillary Electrophoresis Separations and an Electrospray Mass Spectrometry Interface. Rapid Commun. Mass Spectrom. 2000, 14, 1377-1383.

27. Chen, M.; Cook, K. D.; Kheterpal, I.; Wetzel, R. A Triaxial Probe for On-line Proteolysis Coupled with Hydrogen/Deuterium ExchangeElectrospray Mass Spectrometry. J. Am. Soc. Mass Spectrom. 2007, 18 $208-217$.

28. Havlis, J.; Thomas, H.; Sebela, M.; Shevchenko, A. Fast-Response Proteomics by Accelerated In-Gel Digestion of Proteins. Anal. Chem. 2003, 75, 1300-1306.

29. Russell, W. K.; Park, Z.-Y.; Russell, D. H. Proteolysis in Mixed OrganicAqueous Solvent Systems: Applications for Peptide Mass Mapping Using Mass Spectrometry. Anal. Chem. 2001, 73, 2682-2685.

30. Park, Z.-Y.; Russell, D. H. Identification of Individual Proteins in Complex Protein Mixtures by High-Resolution High-Mass-Accuracy MALDI TOF-Mass Spectrometry Analysis of In-Solution Thermal Denaturation/Enzymatic Digestion. Anal. Chem. 2001, 73, 2558-2564. 
31. Peterson, D. S.; Rohr, T.; Svec, F.; Fréchet, J. M. J. Enzymatic Microreactoron-a-Chip: Protein Mapping Using Trypsin Immobilized on Porous Polymer Monoliths Molded in Channels of Microfluidic Devices. Anal. Chem. 2002, 74, 4081-4088.

32. Xie, S.; Svec, F.; Fréchet, J. M. J. Design of Reactive Porous Polymer Supports for High Throughput Bioreactors: Poly(2-Vinyl-4, 4-Dimethylazlactone-co-Acrylamide-co-Ethylene Dimethacrylate) Monoliths. Biotechnol. Bioeng. 1999, 62, 30-35.

33. Kato, M.; Sakai-Kato, K.; Jin, H.; Kubota, K.; Miyano, H.; Toyo'oka, T.; Dulay, M. T.; Zare, R. N. Integration of On-Line Protein Digestion Peptide Separation, and Protein. Identification Using Pepsin-Coated Photopolymerized Sol-Gel Columns and Capillary Electrophoresis/ Mass Spectrometry. Anal. Chem. 2004, 76, 1896-1902.

34. Huang, Y.; Shan, W.; Liu, B.; Liu, Y.; Zhang, Y.; Zhao, Y.; Lu, H.; Tang, Y.; Yang, P. Zeolite Nanoparticle Modified Microchip Reactor for Efficient Protein Digestion. Lab. Chip. 2006, 6, 534-539.

35. Soper, S. A.; Ford, S. M.; Qi, S.; McCarley, R. L.; Kelly, K.; Murphy, M. C. Polymeric Microelectromechanical Systems. Anal. Chem. 2000, 72, 642A651A.

36. McCarley, R. L.; Vaidya, B.; Wei, S.; Smith, A. F.; Patel, A. B.; Feng, J.; Murphy, M. C.; Soper, S. A. Resist-Free Patterning of Surface Architectures in Polymer-Based Microanalytical Devices. I. Am. Chem. Soc. 2005 127, 842-843.

37. Perkins, D. N.; Pappin, D. J. C.; Creasy, D. M.; Cottrell, J. ProbabilityBased Protein Identification by Searching Sequence Databases Using Mass Spectrometry Data. Electrophoresis 1999, 20, 3551-3567.

38. Henkin, J. A.; Jennings, M. E.; Matthews, D. E.; Vigoreaux, J. O. Mass Processing-an Improved Technique for Protein Identification with Mass Spectrometry Data. J. Biomol. Tech. 2004, 15, 230-237.

39. Bigwarfe, P. M. J.; Wood, T. D. Effect of Ionization Mode in the Analysis of Proteolytic Protein Digests. Int. J. Mass Spectrom. 2004, 234, 185-202.

40. Lazar, I. M.; Ramsey, R. S.; Ramsey, J. M. On-Chip Proteolytic Digestion and Analysis Using "Wrong-Way-Round" Electrospray Time-of-Flight Mass Spectrometry. Anal. Chem. 2001, 73, 1733-1739.

41. Seong, G. H.; Heo, J.; Crooks, R. M. Measurement of Enzyme Kinetics Using a Continuous-Flow Microfluidic System. Anal. Chem. 2003, 75, 3161-3167.

42. Koh, W.-G.; Pishkoa, M. Immobilization of Multienzyme Microreactors Inside Microfluidic Devices. Sens. Actuator B Chem. 2005, 106, 335-342.

43. Slovakova, M.; Minc, N.; Bilkova, Z.; Smadja, C.; Faigle, W.; Fütterer, C.; Taverna, M.; Viovy, J.-L. Use of Self Assembled Magnetic Beads for On-Chip Protein Digestion. Lab. Chip. 2005, 5, 935-942.

44. Duan, J.; Sun, L.; Liang, Z.; Zhang, J.; Wang, H.; Zhang, L.; Zhang, W.; Zhang, Y. Rapid Protein Digestion and Identification Using Monolithic Enzymatic Microreactor Coupled with Nano-Liquid ChromatographyElectrospray Ionization Mass Spectrometry. J. Chromatogr. A 2006, 1106, $165-174$.

45. Xi, F.; Wu, J.; Jia, Z.; Lin, X. Preparation and Characterization of Trypsin Immobilized on Silica Gel Supported Macroporous Chitosan Bead. Process Biochem. 2005, 40, 2833-2840.
46. Ru, Q. C.; Zhua, L. A.; Katenhusena, R. A.; Silbermana, J.; Brzeskia, H. Liebmana, M.; Shriver, C. D. Exploring Human Plasma Proteome Strategies: High Efficiency In-Solution Digestion Protocol for Multidimensional Protein Identification Technology J. Chromatogr. A 2006, 1111, 175-191.

47. Liu, Y.; Zhong, W.; Meng, S.; Kong, J.; Lu, H.; Yang, P.; Girault, H. H.; Liu, B. Assembly-Controlled Biocompatible. Interface on a Microchip Strategy to Highly Efficient Proteolysis. Chem. Eur. J. 2006, 12, 65856591.

48. Nesmelova, I. V.; Skirda, V. D.; Fedotov, V. D. Generalized Concentration Dependence of Globular Protein Self-Diffusion Coefficients in Aqueous Solutions. Biopolymers 2002, 63, 132-140.

49. Jin, L. J.; Ferrance, J.; Sanders, J. C.; Landers, J. P. A Microchip-Based Proteolytic Digestion System Driven by Electro-Osmotic Pumping. Lab. Chip. 2003, 3, 11-18.

50. Strader, M. B.; Tabb, D. L.; Hervey, W. J.; Pan, C.; Hurst, G. B. Efficient and Specific Trypsin Digestion of Microgram to Nanogram Quantities of Proteins in Organic-Aqueous Solvent Systems. Anal. Chem. 2006, 78 125-134.

51. Sim, T. S.; Kim, E.-M.; Joo, H. S.; Kim, B. G.; Kim, Y.-K. Application of a Temperature-Controllable Microreactor to Simple and Rapid Protein Identification Using MALDI-TOF MS. Lab. Chip. 2006, 6, 1056-1061.

52. Shadpour, H.; Soper, S. A. Two-Dimensional Electrophoretic. Separation of Proteins Using Poly(Methyl Methacrylate) Microchips. Anal. Chem. 2006, 78, 3519-3527.

53. Owen, S. J.; Meier, F. S.; Brombacher, S.; Volmer, D. A. Increasing Sensitivity and Decreasing Spot Size Using an Inexpensive, Removable Hydrophobic Coating for Matrix-Assisted Laser Desorption/Ionization Plates. Rapid Commun. Mass Spectrom. 2003, 17, 2439-2449.

54. Wei, H.; Dean, S. L.; Parkin, M. C.; Nolkrantz, K.; O'Callaghan, J. P. Kennedy, R. T. Microscale Sample Deposition onto Hydrophobic Target Plates for Trace Level Detection of Neuropeptides in Brain Tissue by MALDI-MS. J. Mass Spectrom. 2005, 40, 1388-1346.

55. Zhang, H.; Caprioli, R. M. Capillary Electrophoresis Combined with Matrix-Assisted Laser Desorption/Ionization Mass Spectrometry; Continuous Sample Deposition on a Matrix-Precoated Membrane Target. J. Mass Spectrom. 1996, 31, 1039-1046.

56. Wall, D. B. Berger, S. J. Finch, J. W. Cohen, S. A. Richardson, K Chapman, R.; Drabble, D.; Brown, J.; Gostick, D. Continuous Sample Deposition from Reversed-Phase Liquid Chromatography to Tracks on a Matrix-Assisted Laser Desorption/Ionization Precoated Target for the Analysis of Protein Digests. Electrophoresis 2002, 23, 3193-3204.

57. Chen, H.S. Rejtar, T; Andreev, V. Moskovets, E- Karger, B. L. High-Speed High-Resolution Monolithic Capillary LC-MALDI MS Using an Off-Line Continuous Deposition Interface for Proteomic Analysis. Anal. Chem. 2005, 77, 2323-2331.

58. Rejtar, T.; Hu, P.; Juhasz, P.; Campbell, J. M.; Vestal, M. L.; Preisler, J. Karger, B. L. Off-Line Coupling of High-Resolution Capillary Electrophoresis to MALDI-TOF and TOF/TOF MS. J. Proteome Res. 2002, 1, 171-179. 